\title{
Cultural Leaders and the Clash of Civilizations*
}

\author{
Esther Hauk ${ }^{\dagger}$ and Hannes Mueller ${ }^{\ddagger}$
}

July 9,2010

\begin{abstract}
This article builds a micro founded model of the clash of cultures. The clash is defined as the parent's fear of a trait change by their child in an overlapping generations model with intergenerational transmission of cultural traits. The extent of the clash is manipulated by cultural leaders who benefit from the cultural education effort by parents. We identify three channels through which the leaders can affect the clash of cultures: (i) by providing beneficial cultural values, (ii) by claims of cultural superiority and (iii) by cultural alienation, i.e. by inducing cultural dislike towards their own group. We show that all three channels can be in the leader's interest but channels (ii) and (iii) reduce the utility of the leader's goup members. This hints to a strong conflict of interest within groups - between the population at large and the benefactors of radicalization. We further show how the use of alienation relates to the economic opportunities available to a group.
\end{abstract}

*Both authors acknowledge the support of Barcelona GSE Research and the government of Catalonia. Hauk thanks the economics department of the London School of Economics for its hospitality and acknowledges financial support from CICYT project number ECO2009-12695 and of the programa de movilidad de profesorado project PR2009-0375.

${ }^{\dagger}$ Institute of Economic Analysis (IAE-CSIC), Campus UAB, 09103 Bellaterra. E-mail: esther.hauk@iae.csic.es

${ }^{\ddagger}$ Institute of Economic Analysis (IAE-CSIC), Campus UAB, 09103 Bellaterra. E-mail: hannes.mueller@iae.csic.es 


\section{Introduction}

The expression "clash of civilizations" or "clash of cultures" has become a winged word after the attacks on the twin towers on 11 September 2001. Originally brought up as term by the historian Bernard Lewis ${ }^{1}$ the expression was made famous by Huntington's book "The Clash of Civilizations and the Remaking of a World Order" (1996). His main hypothesis is that the fundamental source of conflict in the post cold war period will be along cultural and religious lines. In his words: "The fault lines between civilizations will be the battle lines of the future" (Huntington 1993). The debate surrounding the work has received a sense of urgency after the September 11 attacks. Its merit has been debated - not the least for the difficulty of defining a "civilization". ${ }^{2}$ Nonetheless it had an important role in framing the debate on a whole range of issues.

This article builds a micro motivated model of the clash of civilizations in order to explain its importance for public debate and policy actions. To build a model of the clash we adopt the framework of cultural transmission of preferences by Bisin and Verdier (2001). In their model parents maximize the utility of their children by choosing an educational effort that determines the probability that the children receive the parent's cultural trait. If education fails the child adopts the cultural trait of a randomly selected member of the parent's generation (oblique transmission). The "clash" in this framework is the parent's fear that children will adopt a different trait. In our model this fear is quantified by two components: (i) a purely cultural component - the cultural dislike parameter - and by an economic component capturing the economic (dis)advantage of one trait over the other.

However, a realistic micro model of the conflict needs to account for the fact that the propagation of culture and education employs a host of professional agents (Madras school teachers, the pope, politicians, book authors...) who we call "cultural leaders". They receive rents from the population at large (wage payments, book sales or simply the ego rents) in exchange for the provision of cultural characteristics (discussion of moral, speeches, lectures, education, art). In our model the extend of the clash is therefore determined by these cultural leaders who benefit from the educational effort of

\footnotetext{
${ }^{1}$ Lewis used the term first in his article in the September 1990 issue of The Atlantic Monthly titled "The Roots of Muslim Rage".

${ }^{2}$ See also the criticism by Sen (2006) who stresses the complexity of human identities. According to Sen a "clash" on one of these dimensions is a choice not a destiny.
} 
their group members. We analyze how the vested interest of cultural leaders shapes the clash of cultures and the welfare of the population at large.

As a first step we use our model to categorize the channels through which cultural leaders influence the clash of civilizations. These are: (i) the provision of cultural goods that make the culture more appealing to the ingroup, (ii) claims of cultural superiority which makes the outgroup culture less appealing to the ingroup and iii) alienation which makes the ingroup culture less appealing to the outgroup. Clearly, ingroup manipulation (channels (i) and (ii)) affect educational rents directly. Outgroup manipulation (channel (iii)) affects rents indirectly through its effect on the new steady state.

We show that both the provision of cultural goods and claiming cultural superiority is always in the leader's interest because they increase both the spending per parent and the equilibrium group size of the ingroup. More surprisingly, we show that alienation can also be in the interest of the cultural leader. Alienation mobilizes the outgroup against the leader's group which implies a higher educational effort in the outgroup. In the new steady state the leader's group shrinks and both groups exert higher educational effort. The leader now cashes in more per group member. If these extra gains dominate the leader's losses due to the smaller group size, the general radicalization is in the leader's interest. This could explain why recent violence is so often motivated by cultural differences. Culturally motivated violence induces cultural radicalization and is therefore encouraged or at least tolerated by cultural leaders.

Our welfare analysis shows that both claims of superiority and alienation are not in the population's interest. A corollary of this result is that a clash of civilizations caused by negative views on the respective outgroup is truly a conflict between the benefactors of the cultural rents and the population at large. The fact that cultural leaders benefit from radicalization per se, even if it harms the size of their group, leads to perverse incentives for leaders in both camps. Leaders have an incentive to support violence against the outgroup and can use the atrocities conducted against their own group to claim superiority over the outgroup. The fact that leaders might play into each others hands can explain why cultural conflict is so hard to tackle and calm.

The total value of a certain cultural trait does not only depend on people's feelings towards this trait but also on the economic opportunities people with this trait are facing. We capture economic opportunities by allowing for trait dependent wages. This allows us to analyze the interaction between 
economic factors and the use of alienation (e.g. violence). Alienation is not a feasible strategy for the leader if his group is economically very disadvantaged or if alienation leads to even higher economic disadvantages. This has two important implications: (i) a minority that is less disadvantaged economically will be culturally more aggressive. ${ }^{3}$ (ii) institutional/structural limits to discrimination might encourage alienation. While these institutional limits are often set up by the majority group itself, the creation of a minority sector that is protected from wage discrimination can serve an equivalent purpose for the cultural leader of the minority. We show that cultural leaders of sufficiently intolerant minority groups - groups with a sufficiently high level of cultural dislike towards the majority group - will always destroy labor market integration. In doing so, they reduce the size of their own group but benefit from an increased education effort resulting from the possibility of higher alienation under economic isolation of the minority group.

The remainder of the paper is organized as follows. In the next section we will defend the main building block of our model that rents generated in the production of culture are a powerful force in the creation of sentiments of cultural superiority and dislike towards other cultures. Section 3 develops the basic components of our model. Section 4 contains our main results on cultural leaders and the clash of civilizations. In section 5 we provide a detailed analysis of the economic environment. In particular, we examine the incentives for cultural alienation if cultural alienation leads to increased discrimination in the labor market. We also study under which conditions a minority sector that is shielded from the effects of cultural alienation on labor market discrimination will successfully attract minority workers. In Section 6 we connect our results to terrorism, discuss the existence of destructive leaders and relate our results to other conflict models. Section 7 concludes.

\section{Cultural Rents and Cultural Leaders}

The main argument in this article is that the existence of "cultural" rents can be a strong incentive in the creation of a sentiment of fear and hatred. But what are these cultural rents and who benefits from them? To illustrate what we have in mind we provide two examples of important cultural rents enjoyed by religious leaders.

\footnotetext{
${ }^{3}$ This might explain why recent religiously motivated terror attacks were all performed by relatively well-off Muslims.
} 
Example 1 Pakistan is a good example of a country where the state leaders have lost the cultural leadership and educational role to other parties. It is estimated that Madrasas and Mosques in Pakistan gather over 70 billion rupees (around U.S. \$1.1 billion) from resident Pakistanis each year. The explicit aim of Madrasas is the promotion of an Islamic ethos in students. Although human capital accumulation (learning how to read and write for example) is part of the education, a major criticism of these schools is that they do not prepare students for a life outside the Madras and Mosque world.

Attempts of changing the curriculum of Madrasas has been met with fierce resistance by the ulema (teachers running the seminaries). The International Crisis Group summarizes in its report (page 3):

"Any suggestion of change in the traditional sector of Islamic instruction makes the clergy suspicious of government intentions. They are willing to teach non-religious subjects but "secularisation" is their worst fear, and they vow fiercely to resist it."

In fact, the rents (in terms of influence and finance) from running the cultural formation in Pakistan are so large that the Pakistani government has become dependent on the groups running it.

Example 2 The Vatican is another example of cultural leadership with substantial rents. A rough idea of the amount of revenue channeled through the Catholic church is the budget of the Holy See - the episcopal jurisdiction of the Catholic Church in Rome. It alone commands revenue above 230 million Euros per year. And this is only a very small share of the overall revenue. Altogether, the Vatican estimated employment of 408,024 priests of the Catholic Church in 200\%. ${ }^{4}$ In addition, the pope enjoys considerable media attention and influence. His word is taken as representative for over a billion members of the church.

But religious leaders are not the only ones who benefit from cultural efforts of the population. Journalists, politicians and even academics benefit directly from the desire of the population to be culturally educated. The history is crowded with cases where politicians / journalists or academics who act as cultural leaders directly benefit from a cultural conflict in the influence or even resources they receive. A simple example is the book "Clash of Civilizations" itself which has received considerably more attention after 11 September 2001.

\footnotetext{
${ }^{4}$ Annuario Pontificio 2007, Vatican City: Vatican Publishing House.
} 


\section{The Model}

Our basic model is based on Bisin and Verdier's (2001) model of cultural transmission of preferences. In this model a society of size 1 has two possible cultural traits, trait 1 and trait 2 . The fraction of individuals having trait 1 is $q$ and the fraction of individuals having trait 2 is $q_{2}=1-q$. We follow Hauk and Saez-Marti (2002) in the way overlapping generations are modeled: a Poisson birth and death process keeps the population size of active agents constant. $^{5}$

We adopt Assumption 1 from Bisin and Verdier (2001), that parents have imperfect empathy: they can correctly evaluate the economic perspectives of their children but evaluate their child's future utility through their own eyes and therefore would like their children to adopt their own cultural trait. In other words, let $V^{i j}$ be the utility of a type $i$ parent of having a trait $j$ child. Imperfect empathy implies that $V^{i i}>V^{i j}$ so that $\Delta_{1}=V^{11}-V^{12}>0$ and $\Delta_{2}=V^{22}-V^{21}>0$. The parameters $\Delta_{1}$ and $\Delta_{2}$ can therefore be interpreted as the fear of a trait change within the family.

Parents choose their education effort $d_{i}$ which determines the probability that their child will be of their own type. We assume that the costs of education are $C\left(d_{i}\right)=\frac{1}{2} d_{i}^{2}$. If education fails, the child bumps into a randomly chosen member of the parent's society and copies his preferences. Therefore the probability $P^{i j}$ of a type $i$ parent to have a type $j$ child are given by:

$$
\begin{aligned}
P^{11} & =d_{1}+\left(1-d_{1}\right) q \\
P^{22} & =d_{2}+\left(1-d_{2}\right)(1-q) \\
P^{12} & =\left(1-d_{1}\right)(1-q) \\
P^{21} & =\left(1-d_{2}\right) q
\end{aligned}
$$

and $d_{i}$ is chosen to maximize

$$
\max _{d_{i}} U_{i}=P^{i i} V^{i i}+P^{i j} V^{i j}-\frac{1}{2} d_{i}^{2}
$$

\footnotetext{
${ }^{5}$ The survival probability of an active agent is $\lambda$ each period. With probability $1-\lambda$ an active agent has a child without any predetermined preferences who will becomes active the next period. For simplicity we look at life-time values. This saves on notation. If we only looked at per period values everything would have to be multiplied by $\frac{1}{1-\lambda}$ to get life-time utilities.
} 
which for the different groups can be written as

$$
\begin{aligned}
& \max _{d_{1}} V^{11}-(1-q)\left(1-d_{1}\right) \Delta_{1}-\frac{1}{2} d_{1}^{2} \\
& \max _{d_{2}} V^{22}-q\left(1-d_{2}\right) \Delta_{2}-\frac{1}{2} d_{2}^{2}
\end{aligned}
$$

leading to the following optimal education efforts

$$
\begin{aligned}
& d_{1}=\Delta_{1}(1-q) \\
& d_{2}=\Delta_{2} q
\end{aligned}
$$

which means that educational effort is higher the greater the fear of a trait change and the smaller the respective trait group. Direct and oblique socialization are cultural substitutes.

The population dynamics can be written as follows:

$$
\begin{aligned}
q_{t+1}= & \lambda q_{t}+(1-\lambda)\left(q_{t} P_{t}^{11}+\left(1-q_{t}\right) P_{t}^{21}\right) \\
= & \lambda q_{t}+(1-\lambda) q_{t}\left(\left(d_{1}+\left(1-d_{1}\right) q_{t}\right)+\left(1-q_{t}\right)\left(1-d_{2}\right)\right) \\
& q_{t+1}-q_{t}=(1-\lambda) q_{t}\left(1-q_{t}\right)\left(d_{1}-d_{2}\right)
\end{aligned}
$$

Hence in steady state

$$
0=(1-\lambda) q(1-q)\left(d_{1}-d_{2}\right)
$$

which has three rest points, $q=0$ and $q=1$ and the interior rest point $d_{1}=d_{2}$ which by Proposition 1 in Bisin and Verdier (2001) is the only stable rest point. Hence the stable steady state is determined by

$$
\Delta_{1}\left(1-q^{*}\right)=\Delta_{2} q^{*}
$$

so that the equilibrium group size of trait 1 is given by

$$
q^{*}=\frac{\Delta_{1}}{\Delta_{1}+\Delta_{2}} .
$$

We will concentrate our analysis on this equilibrium $q^{*}$ and consider which steady state outcome would be the most preferred outcome of the cultural leader of group 2. We will refer to trait 1 as the "majority" trait and trait 2 as the "minority" trait.

Note that the equilibrium group size and the educational effort can be expressed as a function of $\Delta_{1}$ and $\Delta_{2}$, the fear of a trait change within the family. We first examine what determines this parameter. 


\subsection{Economic Opportunities and Cultural Dislike}

We assume that each trait has an intrinsic value $u_{i j}$ which is the pleasure derived by a type $i$ parent if his child holds cultural value $j$. Since by assumption parent's care about the survival of their cultural trait $u_{i i} \geq u_{i j}$. We will refer to $f_{i} \equiv u_{i i}-u_{i j}$ as cultural dislike. In order to model the clash of civilizations we assume that cultural leaders can affect these values. Details are discussed in section 4 .

Apart from cultural values the utility of parents is also determined by the economic opportunities of their offsprings. We assume that these are objectified, i.e. the perspective on economic opportunities is independent of the trait. In general, we will refer to the life-time economic opportunities as wages $w_{i}$ where $i$ refers to the cultural trait of the child. We assume that $w_{1} \geq w_{2}$. This assumption can reflect two different economic environments: (i) everybody works in the same sector but there is wage discrimination against cultural trait 2 (or equivalently this trait has a lower productivity), (ii) the different traits work in separated sectors and the minority sector is less productive.

As a first step it is useful to combine the cultural and economic factors in the expressions of $V^{i j}$ (the utility of a type $i$ parent of having a trait $j$ child). They are

$$
\begin{aligned}
V^{11} & =u_{11}+w_{1} \\
V^{12} & =u_{12}+w_{2} \\
& =u_{11}-f_{1}+w_{2} \\
V^{22} & =u_{22}+w_{2} \\
V^{21} & =u_{22}-f_{2}+w_{1} .
\end{aligned}
$$

where we have rewritten the utility after a trait change with the help of our definition of cultural dislike. The fear of a trait change for the majority, $\Delta_{1}$, can be written as

$$
\Delta_{1}=f_{1}+\left(w_{1}-w_{2}\right)
$$

where the first term reflects the cultural dislike while the second term reflects the loss of economic opportunity of the child. Keep in mind that the fear of a trait change is what gives parents an incentive to educate their children. Hence, majority parents are motivated both by their cultural preferences and 
the anticipation of their children's economic well-being. ${ }^{6}$ In the minority, fear of a trait change takes the form

$$
\Delta_{2}=f_{2}-\left(w_{1}-w_{2}\right)
$$

which follows the logics of the majority except for now, unequal economic opportunities demotivate educational effort. For cultural survival to be possible $\Delta_{2}>0$. Hence $\left(u_{22}-u_{21}\right)>\left(w_{1}-w_{2}\right)$ is needed for the survival of trait 2 . In other words, the minorities dislike for the majority trait has to compensate the wage differential if the minority trait is to survive in the long run.

The overall level of fear of a trait change in society is

$$
\Delta_{1}+\Delta_{2}=f_{1}+f_{2}
$$

and as shown above the equilibrium size of the majority is given by

$$
q^{*}=\frac{f_{1}+\left(w_{1}-w_{2}\right)}{f_{1}+f_{2}}
$$

which implies that the equilibrium size of the majority is increasing in the extent of wage discrimination against the minority and the cultural dislike of the majority towards the minority.

In what follows we use these results to explain how cultural leaders and the clash of civilizations are linked.

\section{Cultural leaders and the Clash of Civiliza- tions}

Our explanation of the clash of civilizations hinges on two assumptions. First, we assume that cultural leaders benefit directly from the educational efforts of their group, i.e. by increasing the attention, power or income they receive. In order to model this we assume that the leader maximizes the sum of cultural expenses in the minority given by

$$
U_{2 l e a d e r}=\frac{1}{2} d_{2}^{2}(1-q)=\frac{1}{2} \Delta_{2}^{2} q^{2}(1-q) .
$$

\footnotetext{
${ }^{6}$ In this basic specification cultural dislike does not affect purely economic variables which allows us to isolate purely cultural effects. This assumption is relaxed in Section 5 where we explicitely discuss economic opportunities and their possible link to cultural dislike.
} 
Intuitively cultural leaders benefit from the extent of fear of a trait change in their group $\Delta_{2}$ and the size of the group $(1-q)$. The term $q^{2}$ captures the existence of a free rider problem in cultural transmission. Parents have an incentive to free-ride on the education of society at large. The larger the group of the leader, the more free-riding opportunities society offers. Hence, per capital effort is decreasing in group size.

The second assumption is that cultural leaders can affect the extent of the clash (directly or indirectly). Our discussion of the fear of a trait change parameters above allows us to identify three cultural channels for this influence. A fourth channel, namely the manipulation of the economic opportunities of the different traits, is discussed in Section 5.

Cultural Goods: leaders can provide cultural goods that can only be consumed within the setting of the trait. In the model this implies a rise of $u_{i i}$. Examples are the provision/teaching of rules or knowledge that help individual or community life, creation of art that are complementary to other works in the culture or simply entertainment that is accessible only for those having the trait.

Cultural Superiority: if the possibility of providing utility-enhancing cultural goods is very costly, leaders might try to lower, $u_{i j}$, which is the perception that parents have of the other culture. Examples are the description of the other cultural trait as barbaric, stressing the lack of freedom in that group or the use of religious arguments (the prospect of hell for example) to instill fear of a trait change. An important driver of this sentiment are stories of injustices or atrocities towards the ingroup as in Glaeser (2002).

Cultural Alienation: another possibility of cultural leaders is to increase the fear of a trait change within the other group by lowering $u_{j i}$. Most prominently this is achieved through violent acts/terror against members of the other trait which make explicit reference to the fact that the ingroup trait is responsible for the violence. The ingroup trait will be regarded as radical, harmful or barbaric by the outgroup. To some degree this is what happened after the September 11 attacks. But, of course, there are other possibilities for alienation. Provocations, threats or public displays of hatred in the name of the trait by religious and political leaders can be effective ways to alienate other traits. Indeed, cultural conflicts often feature actions by cultural leaders that appear irrational at first sight because they clearly discredit the ingroup.

We ignore the possibility of providing cultural goods for the other group, i.e. raising $u_{j j}$. Our rational is that for leader $i$, the benefits of raising $u_{i i}$ 
are higher and, thus, as raising $u_{i i}$ and $u_{j j}$ cost the same, $u_{j j}$ will never be raised.

We now analyze the incentives of the cultural leaders to follow different clash strategies. Both production of cultural goods and claims of cultural superiority over the outgroup are indeed common by both political or religious leaders. Our model confirms that they are in the interest of cultural leaders. ${ }^{7}$

Proposition 1 If cultural leaders can affect $f_{2} \equiv u_{22}-u_{21}$ they will try to maximize it. The minority population always supports an increase of $u_{22}$ and never supports a decrease of $u_{21}$.

Proof. See appendix.

In words, the cultural leader has a large interest in raising cultural dislike of the minority group. ${ }^{8}$ This claim can be either supported through the provision of cultural values (raising $u_{22}$ ) or through making the other culture appear inferior (lowering $u_{21}$ ). Since parents have to live with a chance that their children change culture, the latter strategy is less desirable from their perspective as it increases anxiety.

More surprisingly, cultural leaders can have an interest to alienate the outgroup.

Proposition 2 Alienation, i.e. an increase of cultural fear (lower $u_{21}$ ) towards the minority is supported by the cultural leader as long as the minority is sufficiently large $\left(q^{*}<\frac{2}{3}\right)$. Alienation it is not in the minorities interest.

Proof. See appendix.

Proposition 2 is our main finding. The intuition for this result is that the leader prefers a small radical group to a large unmotivated group. An increase in cultural dislike towards the minority leads to an increased individual effort in education and hence to more radicalization. The optimum from the point of view of the leader is reached when the minority is sufficiently small. The

\footnotetext{
${ }^{7}$ In our main analysis we abstract from the cost side of changing $f_{1}$ or $f_{2}$. The analysis reveals when the marginal benefit of increasing $f_{1}$ or $f_{2}$ is positive, and hence might be in the leader's interest. If increasing $f_{1}$ and $f_{2}$ is costly, leaders would choose the point where this marginal benefit equals the marginal cost. We will discuss costly increases of $f_{1}$ and $f_{2}$ later in this section.

${ }^{8}$ For costly changes in $f_{2}$, the result can be interpreted as saying that cultural leaders will maximize $f_{2}$ subject to the cost of producing it.
} 
appendix reveals the exact mechanism. A rise in cultural dislike towards the minority affects the minority indirectly. It increases the effort of majority parents, shrinks the minority and therefore forces minority parents to become more radical to make up for the decrease in free-riding possibilities.

One interesting question is how the differences in economic opportunities between the two traits affects the leader's incentive for cultural alienation. To answer that question note that by

$$
q^{*}=\frac{f_{1}+\left(w_{1}-w_{2}\right)}{f_{1}+f_{2}} .
$$

the wage gap $\left(w_{1}-w_{2}\right)$ increases the size of the majority $q^{*}$. Remember that for optimal alienation the leader strives for $q^{*}=\frac{2}{3}$. If $q^{*}$ increases due to an increase in $\left(w_{1}-w_{2}\right)$ then $f_{1}$ needs to fall to decrease $q^{*}$ again.

Corollary 1 If cultural leaders maximize their utility using alienation $\left(f_{1}\right)$, alienation decreases with the wage gap $\left(w_{1}-w_{2}\right)$. In other words, a minority that is less disadvantaged economically will be culturally more aggressive.

Corollary 1 might appear puzzling. It stems from the fact that, in the leader's optimum, wage discrimination and alienation are substitutes. If the leader's group is economically very disadvantaged the pressures on the minority to change trait are large. This implies that alienation as a strategy of increasing revenue is not feasible. The fact that recent religiously motivated terror acts were all performed by relatively well-off Muslims could be seen as evidence that this concept of a "capacity for alienation" is not too far fetched. ${ }^{9}$

We now turn to the issue when the leader prefers ingroup manipulation (changing $f_{2}$ ) to outgroup manipulation (changing $f_{1}$ ).

Proposition 3 If an increase of $f_{2}$ and an increase of $f_{1}$ have the same cost to the leader, the leader prefers to increase $f_{2}$ for all $q^{*}>\frac{2}{5}$.

Proof. See appendix.

\footnotetext{
${ }^{9}$ Empirical studies demostrate that terrorist operatives tend not to be from societies' worst-off socioeconomic group. On the contrary, they have above average educational achievements and are less likely to live in poverty than the average person (Krueger and Malechova (2003), Berribi (2007)). Bueno de Mesquita (2005) provides a theoretical model for these findings.
} 
It will us useful to illustrate Proposition 3 for the case in which both increasing $f_{1}$ and increasing $f_{2}$ is costless for the leader. Proposition 2 stated that alienation was desirable for the leader for all $q<\frac{2}{3}$. Hence the leader will switch from cultural alienation to increasing $f_{2}$ at $q=\frac{2}{5}$. It is important to note that the effect of these two strategies on $q^{*}$ is exactly opposite. While increasing $f_{2}$ raises $q^{*}$, increasing $f_{1}$ lowers it. The result is a mixture between provision of cultural goods and alienation at a minority size $1-q^{*}=\frac{3}{5}$.

If changing $f_{1}$ and $f_{2}$ is not costless, Proposition 3 still tells us that the marginal benefit from increasing $f_{2}$ is bigger than the marginal benefit from increasing $f_{1}$ if and only if $q^{*}>\frac{2}{5}$. But now the leader will also have to evaluate the marginal cost of each strategy. Recall that raising $f_{2}$ can be done in two ways, by the provision of utility enhancing cultural goods and by successful claims of cultural superiority leading to utility losses of the leader's group. While the provision of positive cultural goods is likely to be costly, claims of cultural superiority might be cheap, especially if they can be rooted in actions from the other group. The present "clash" has generated a host of atrocities on both sides that can be used to claim cultural superiority. Hence, it is reasonable to assume that at least at some point increasing $f_{2}$ is cheaper through claims of cultural superiority leading to a conflict of interests between the leader and his group. For similar reasons, glorification of past atrocities or tolerance towards present atrocities committed by the own group can be relatively cheap methods of cultural alienation (increasing $f_{1}$ ).

Claims of cultural superiority and attempts to alienation are not beneficial for the population at large. A comparison of propositions 1 and 2 allows us to make statements about the conflict of interest between cultural leaders and the general public. Clearly, due to symmetry cultural leaders of the majority will have the same interest as their peers in the minority. Similarly the majority population shares the interest in $u_{i i}$ with the minority.

Corollary 2 Cultural leaders of both majority and minority share an interest in escalating the clash as long as both groups are not too unequal in size. Members of the groups prefer a setting with high $u_{i i}$ and low $u_{i j}$.

Corollary 2 delivers a striking re-interpretation of the "clash of civilizations". The clash is to a large degree due to the existence of cultural leaders in both groups who have an incentive to provoke intolerance and fear on both sides of the clash. While the population benefits from the production of positive value it is affected negatively by the fear created by an atmosphere 
of intolerance. Increasing radicalization on both sides requires an increasing amount of investment in education - this furthers the interest of leaders.

The above analysis has taken the economic environment as given. However, the actions of cultural leaders might change this environment. We turn to this issue in the next section.

\section{The Role of Economic Opportunities}

The above analysis assumed that cultural manipulations had no effects on the economic opportunities of the groups. However, it is likely that if the minority leader successfully uses the strategy of cultural alienation, this does not only affect how much cultural dislike the majority parents feel in case of a trait change of their child, but also the economic opportunities of the members of the minority. In other words, the majority might increase their fear towards the minority and this increased fear might translate into increased discrimination. ${ }^{10}$

Indeed there are several empirical studies that suggest an effect of major terror attacks on labor market discrimination. Kaushal et al. (2007) find a real wage decline of $9-11 \%$ and reduced interstate mobility for first- and second generation Arab and Muslim men in the US following 9/11. Similarly, Dávila and Mora (2005) find evidence of wage drop of Arab men in the US after 9/11. Rabby (2007) finds similar effects using household survey data sets to estimate the effects of $9 / 11$ and the July 2005 London bombing on the labor market outcomes of Arabs, South-Asians and Muslims living in the US and in the UK in a difference-in-differences framework.

First, it will be helpful to understand whether or not increased discrimination can be in the minority's leader's interest.

\footnotetext{
${ }^{10}$ The theoretical literature offers two mechanisms how this could happen: (i) cultural alienation might lead to an increased taste for discrimination (Becker (1971)) which would lead to more equilibrium discrimination in search models with firm discrimination (Black (1995), Rosen (1997)), co-worker discrimination (Sasaki (1999)). (ii) The statistical discrimination literature (e.g. Phelps (1972), Aigner and Cain (1977), Morgan and Vardy (2009) and Cornell and Welch (1996)) offers an alternative explanation for increased discrimination after alienation even in the absence of a taste for discrimination. This literature suggests that empoyers have to rely on interviews to predict an employee's productivity and that interviews with somebody belonging to a different culture produce noisier signals than interviews with members from the same culture. Cultural alienation increases the nose of the signal even further.
} 
Proposition 4 If the only effect of alienation is to increase wage discrimination towards the minority the leader benefits from alienation as long as the minority is sufficiently large $\left(q^{*}<\frac{2}{5}\right)$

Proof. See Appendix

Wage discrimination is only in the leader's interest if the minority is a very large group. This restriction stems from the fact that an increase in wage discrimination demotivates minority educational effort if children are likely to take on the majority trait without effort (for all $q \geq \frac{1}{2}$ ). As the minority grows it is increasingly immune to the economic lure (think of the extreme of $q=0$ ). The situation is then similar to the one described in proposition 2. Wage discrimination leads to high effort in the majority which, in turn, forces the minority to exert effort in order to prevent group decline.

Proposition 4 suggests that cultural alienation might be less attractive for the leader if economic opportunities of the minority are more affected. We now check whether this intuition is confirmed in a formal model. Assume that

$$
w_{1}-w_{2}=\alpha f_{1}
$$

where $\alpha \geq 0$ measures how much cultural dislike translates into discrimination. This leads to the following fear parameters:

$$
\begin{aligned}
\Delta_{1} & =(1+\alpha) f_{1} \\
\Delta_{2} & =f_{2}-\alpha f_{1} \\
\Delta_{1}+\Delta_{2} & =f_{1}+f_{2}
\end{aligned}
$$

The stable equilibrium is given by

$$
q=\frac{(1+\alpha) f_{1}}{f_{1}+f_{2}}
$$

Indeed,

Proposition 5 The optimal level of cultural alienation $f_{1}$ is decreasing in $\alpha$.

Proof. See appendix

Proposition 5 has the following surprising implication: 
Corollary 3 If economic opportunities are less affected by cultural alienation the strategy becomes more attractive for the cultural leader.

In other words, restrictions on wage discrimination - instead of helping the minority - might backfire because they increase the leader's capacity for alienation. We can think of two different reasons why wage discrimination does not react to alienation. (i) Institutional constraints prevent majority employers from discriminating against the minority. (ii) The minority has developed its own sub-economy that is independent of cultural sentiments in the majority. ${ }^{11}$ Corollary 3 suggests that the cultural leader might be interested in developing such a minority sector. We turn to this question next.

\subsection{A minority sector}

In an environment where cultural alienation leads to more discrimination, the creation of a minority sector might benefit the cultural leader's interest since it puts an upper bound to wage discrimination. If discrimination is too high, everybody will move to the minority sector. Formally,

$$
\begin{aligned}
V^{11} & =u_{11}+w_{1} \\
V^{12} & =\left(u_{11}-f_{1}\right)+\max \left\{w_{2}, w_{1}-\alpha f_{1}\right\} \\
V^{22} & =u_{22}+\max \left\{w_{2}, w_{1}-\alpha f_{1}\right\} \\
V^{21} & =\left(u_{22}-f_{2}\right)+w_{1}
\end{aligned}
$$

where $w_{2}$ is now the wage in a separate minority sector while $w_{1}-\alpha f_{1}$ describes the wage of an integrating minority member.

This model has two equilibrium candidates:

1. In the first candidate $q^{S}$ there is separation in the labor market and cultural alienation does not have an effect on discrimination. Since $\Delta_{2}$ is totally independent from $f_{1}$ we know from the previous analysis that

\footnotetext{
${ }^{11}$ It is not uncommon that the minority develops an informal sector that relies on minority social networks for enforcement etc. In an international context the lack of an economic backlash is most obvious in oil producing countries. Economic opportunity in these resource rich countries remains independant from the cultural feeling of the West towards these countries.
} 
the leader sets $f_{1}^{S}$ such that

$$
q^{S}=\frac{f_{1}^{S}+\left(w_{1}-w_{2}\right)}{f_{1}^{S}+f_{2}}=\frac{2}{3},
$$

hence

$$
f_{1}^{S}=2 f_{2}-3\left(w_{1}-w_{2}\right)
$$

2. In the second candidate $q^{I}$ the labor market is integrated and cultural alienation affects the amount of labor market discrimination. Hence $q^{I}$ is given by equation (12) namely by

$$
q^{I}=\frac{(1+\alpha) f_{1}^{I}}{f_{1}^{I}+f_{2}}
$$

and the optimal fear level was derived in Appendix E as

$$
f_{1}^{I}=f_{1}^{\alpha}=\frac{f_{2}}{4 \alpha}\left(\sqrt{(1+5 \alpha)^{2}+16 \alpha}-(1+5 \alpha)\right) .
$$

Observe that separation will never be an equilibrium if the minority prefers to work in the discriminating majority sector for the optimal fear parameter of the separation equilibrium candidate $f_{1}^{S}$. Similarly, labor market integration will never be an equilibrium if at $f_{1}^{I}$ the minority prefers the minority sector. If both equilibria are feasible the cultural leader will implement the equilibrium that maximizes his utility. Proposition 6 characterizes the equilibrium.

Proposition 6 The equilibrium outcomes are as follows

1. Labor market integration $q^{I}$ if the cultural dislike of the minority towards the majority is low, namely

$$
f_{2}<\frac{1+3 \alpha}{2 \alpha}\left(w_{1}-w_{2}\right)
$$

2. Labor market separation $q^{S}$ if the cultural dislike of the minority towards the majority is high. In particular,

$$
f_{2}>\frac{4\left(w_{1}-w_{2}\right)}{\sqrt{(1+5 \alpha)^{2}+16 \alpha}-(1+5 \alpha)} .
$$


3. For intermediate levels of cultural dislike of the minority towards the majority, namely

$$
\frac{(1+3 \alpha)\left(w_{1}-w_{2}\right)}{2 \alpha}<f_{2}<\frac{4\left(w_{1}-w_{2}\right)}{\sqrt{(1+5 \alpha)^{2}+16 \alpha}-(1+5 \alpha)}
$$

the religious leader will induce labor market separation $q^{S}$ whenever

$$
(1-\sqrt{B}) f_{2}>\left(w_{1}-w_{2}\right)
$$

and the integration equilibrium $q^{I}$ otherwise where $B<1$ is defined by equation (25) in appendix F. Moreover $q^{I}<q^{S}$.

\section{Proof. See appendix}

Proposition 6 tells us that only leaders of sufficiently intolerant (high $f_{2}$ ) minority groups will be able to destroy labor market integration. Since the minority group will only be willing to work in the majority sector when there is little cultural alienation, the proportion of the minority in the integrated labor market is higher than in the separated labor market when both labor markets are possible. Hence inducing the switch from the integration equilibrium to the separation equilibrium implies that the leader will cash in the education effort of fewer people. However, per capita education effort will be higher because direct and oblique socialization are cultural substitutes. Moreover, the effect of cultural alienation is different in the integrated and the separated labor market. In the integrated labor market cultural alienation has an additional effect, namely it increases wage discrimination and thereby reduces the attractiveness of being a member of the minority. Once this effect is gone due to a switch to the minority sector, the marginal benefit of cultural alienation for the cultural leader makes a jump which explains why labor market separation might be optimal for the leader.

The following proposition tells us how the creation of a minority sector depends on the other variables of the model.

Proposition 7 The successful creation of a minority sector becomes more likely the smaller $w_{1}-w_{2}$, the higher $\alpha$ and the higher $f_{2}$.

Proof. See appendix

In the appendix we show that conditions (18) and (19) are more likely to hold and condition (17) is more likely to be violated the smaller $w_{1}-w_{2}$, the 
higher $\alpha$ and the higher $f_{2}$. The intuition is as follows. The smaller $w_{1}-w_{2}$, the more attractive is the minority sector per se. Similarly, the higher the possible wage discrimination when working in the majority sector (high $\alpha$ ), the more attractive the minority sector becomes where this wage discrimination is avoided. Moreover, high $\alpha$ limits the possibility of the cultural leader to induce cultural alienation in the integration equilibrium considerably. Hence, it is worthwhile for the leader to increase cultural alienation sufficiently to get to the separation equilibrium where the group is protected from discrimination.

Proposition 7 implies that small changes in cultural dislike towards the majority (higher $f_{2}$ ) or a build-up of economic opportunities for the minority outside of the majority's economy (lower $w_{1}-w_{2}$ ) can trigger drastic changes in incentives to alienate. Once the thresholds given in conditions (18) and (19) are fulfilled the leader will want to drive $f_{1}$ up considerably. This in turn will lead to more economic discrimination (lower $\left.w_{1}-\alpha f_{1}\right){ }^{12}$

\section{Discussion}

We now discuss several aspects of our results. In particular, we explain why the framework presented here could shed some lights on the use of terrorism. We then discuss the existence of destructive leaders and how our results relate to other models of conflict.

\subsection{Terrorism}

Our model can explain certain aspects of recent terror attacks if we interpret terror as a way to achieve cultural alienation. However, before we extend these arguments it is useful to review the related literature on the effects of terror.

In the complex modern world our evolutionary response to terror fuels a "us/them" mentality and a response of hatred against the outgroup. ${ }^{13}$

\footnotetext{
${ }^{12}$ If we introduced economic heterogeneity of minority members then this effect of alienation could imply a re-enforcement of the mechanism. More minority members leaving the majority sector would make the minority increasingly immune to economic discrimination and, hence, make alienation increasingly attractive for the leader.

${ }^{13}$ For a nice description of the psychology of terror see McCauley (2007). For a connection to hatred see Freyd (2002).
} 
Hence, terror attacks are likely to emphasize cultural identities and cultural differences. In addition, cultural world views and self-esteem act as anxiety buffers. Reminders of one's own mortality intensify efforts to uphold cultural world-views and self-esteem, ${ }^{14}$ in particular they increase nationalism and prejudice $^{15}$ and the support of charismatic leaders. ${ }^{16}$

Apart from psychological experiments there is a substantial body of empirical evidence that confirms that terror increases prejudice. According to the FBI, hate crimes targeting Muslims increased by $1600 \%$ from 2000 to 2001. Also hate crimes against people of Middle Eastern origin increased from 354 attacks in 2000 to 1501 attacks in 2002 (Oswald, 2005). Sheridan (2006) investigates levels of self-reported racial and religious discrimination in a sample of 222 British Muslims. Respondents indicate that following September 11th, 2001, levels of implicit or indirect discrimination rose by $82.6 \%$ and experiences of overt discrimination by $76.3 \%$. Kam and Kinder (2007) provide evidence that American ethnocentrism (defined as the commonplace human tendency to partition the social world into virtuous ingroups and nefarious outgroups) powerfully underwrites support for the war on terrorism, and the strength of the relationship between ethnocentrism and opinion is influenced in part by the extraordinary events of 9/11. Hitlan et al. (2007) examine prejudice and perceived threat toward Mexican and Arab immigrants/immigration along the U.S./Mexico border before and after 9/11. While American identity is shown to be positively related to higher prejudice and threat perceptions, prejudice and symbolic threat perception of Arab immigrants increased sharply after the September 11 attacks. Canetti-Nisim et al. (2009) provide evidence that in Israel terrorism induces nondemocratic attitudes that threatens minorities.

The above evidence suggests that terror attacks can indeed work as a tool for cultural alienation. According to our theory a second-order effect of this

\footnotetext{
${ }^{14}$ This theory called "terror management theory" (TMT) is due to Greenberg et al. (1986) and Solomon et al. (1991). TMT has been empirically confirmed in over 175 published experiments (Cohen et al. (2004)).

${ }^{15}$ Das et al. (2009) show that terrorist news increase prejudice about outgroups. Bar-Tal and Labin (2001) study the effects of terrorist attacks carried out by Palestinian extremists on Israel's stereotypes, social distance etc towards Palestinians, Jordanians and Arabs. While in general adolescents' perceptions were differentiated towards the three target groups, most negative towards Palestians, most positive towards Jordans (no conflict with Israel) and intermediate towards Arabs, the terrorist attacks caused all stereotypes of all three groups to change in a negative direction.

${ }^{16}$ see Cohen et al (2004) and Landau et al. (2004))
} 
alienation should be that Muslims increase their cultural efforts. In other words, terror attacks should have led to a radicalization on both sides. Unfortunately good data that would allow for a comparison of Muslim attitudes across time is not available. However, the degree to which being Muslim is forced onto Muslims by a reaction of the majority can be seen by accounts like that of Sara Wajid, a Muslim journalist living in the UK in the aftermath of the London terror attacks July 2005:

But most British Muslims have experienced the fetishisation of our religious identity over our citizenship - and are exhausted by it. A lower profile would be great. In fact, a return to the closet would be a blessed relief. I miss the relative anonymity of being British Asian. ${ }^{17}$

In addition, there are indicators, like the rise of Muslim faith based schools ${ }^{18}$ that suggest that Muslim identity amongst immigrants could have strengthened. This strengthening of Muslim identity is hard to explain other than through a second order effect like the one present in our model.

Another corollary of our findings is that there are incentives to support terror for cultural leaders even when these attacks do not succeed in reaching their political goals. It is therefore not a surprise that terror takes place even if it bolsters support for more hawkish politicians in the attacked group. ${ }^{19}$

Our analysis reveals that the incentives to use terror depend very much on the economic environment of the minority group. Corollary 1 indicates that leaders of economically weak groups will be less tempted to conduct terrorism. The reason is that the use of alienation requires a basic attractiveness of the group which is eroded by trait-related economic misery.

Corollary 4 tells us that at the margin, restrictions on wage discrimination increase the use of terror. Hence, if the minority is forced to work in the majority sector the absence on any institutional restriction on wage discrimination is actually an anti-terror device. However, by proposition 7 the lack of institutional restriction on wage discriminations (high $\alpha$ ) increases the probability of a successful creation of the minority sector where wages are sheltered from the majority's sentiments towards the minority. If the

\footnotetext{
${ }^{17}$ New Statesman 2009, p.

${ }^{18}$ In the UK, for example, the Ofsted 2005 annual report indicates a near doubling in the number of independent faith schools to about 300, compared with 170 in 2003 . These include more than 100 Muslim schools and about 100 run by evangelical Christian groups. (Source: The Times, 18 January 2005)

${ }^{19}$ Berrebi and Klor (2008) find, for example, that terror attacks in Israel lead to more support for right-wing parties.
} 
minority is economically segregated, leaders are more tempted to support alienation. In other words, economic isolation makes cultural alienation a more attractive strategy.

Whether leaders use terrorism as a strategy for cultural alienation depends on its costs relative to other channels. Increasing $f_{1}$ is a costly strategy if the leader has to sponsor violence and terror. However, if all that is required is approval of an already existing (maybe even independent) terror organization and words of encouragement, increasing $f_{1}$ can be surprisingly cheap. This might explain why terror organizations with a strong religious and cultural emphasis are not easily condemned by leaders from their own culture. How central terrorist organizations are to the clash of civilizations might be one of the reasons why some are longer lived than others.

\subsection{Destructive leaders}

The above model takes the existence of leaders as given. In this context it shows that leaders can benefit from cultural alienation and cultural superiority at the expense of the utility of the population. Hence, in as far as alienation and claims of cultural superiority can be effective, cultural leaders will use them. But this harms the population at large. So why does the population fail to replace these destructive leaders?

While we will hint at a few reasons below, a detailed answer to this question is left for future research. It would require to model competition between leaders. This competition can be internal or external. If there is internal competition within the trait to become a cultural leader potential candidates would offer "trait platforms" and are then selected by the population. If parents foresee the consequences of their leader choices correctly, internal competition is likely to be an effective tool to lower abuses. However, once a leader is in office, he will have access to the cultural rents and might use these rents to buy off potential challengers and to establish a monopoly position and then renege on his platform. Moreover, even if leaders do not actively engage in cultural alienation and cultural superiority claims and only provide positive cultures, they have no incentives to silence any attempts of alienation and cultural superiority claims that arise among their followers. They will free-ride on any radical that exists. Additionally, leader selection is often institutionalized and leaders might manipulate these institutional rules 
in their favor. ${ }^{20}$

External competition to a cultural leader arises from the possibility to launch a new cultural trait. This way of creating competition is less likely to align incentives between population and leaders as the incentive to claim cultural superiority might even be amplified with rising competition. As shown by Bisin et al. (2008) and Montgomery (2008) if there are more than two cultural traits $\Delta_{i}>0$ is not sufficient for cultural survival. Using the same assumption on educational costs as in the present article, these papers show that the two types with the highest $\Delta_{i}$ - the two most "radical" types - survive but types with lower $\Delta_{i}$ might become extinct. ${ }^{21}$ Hence, successful entry of a new type requires either strong economic advantages associated with the type or a high cultural dislike towards other types or both. Cultural traits with less economic possibilities need to emphasize their cultural superiority: otherwise they might simply be eliminated in the fight for cultural survival.

Whatever the reasons why the population tolerates destructive leaders, destructive cultural leadership is an empirical fact. Alienation and claims to superiority implies a rise in conflict and numerous historical examples have shown that rising conflict has the perverse effect of rallying people behind its leaders. ${ }^{22}$ As explained above, these effects are especially important if cultural leaders from both sides of the "clash" collude by simultaneously increasing alienation.

\footnotetext{
${ }^{20}$ Two striking features of the selection of especially religious leaders are that often these leaders are elected for life and that there exist culturally entrenched institutions that prohibit material wealth to these leaders. However, this restriction is often only nominal: the leader does not own personal wealth but manages at least to some extent the institutional wealth.

${ }^{21}$ The proofs require a constant $\Delta_{i}$ for all types. This is the case in the present paper.

${ }^{22}$ The rally around the flag effect is mainly studied for leaders involved in interstate conflict. See e.g. Baker and Oneal (2001) for rally around the flag effects in the US and Lai and Reiter (2005) for rally around the flag effects in the UK.

Colaresi (2004) uses event history techniques to analyze the likelihood of all state leaders between 1950-1990 to be replaced from office depending on whether they were more or less aggressive than the leader of the rival state in a conflict situation. He finds strong evidence that leaders who are less agressive than their rivals pay an electorial price (are more likely to lose office).
} 


\subsection{Relation to other conflict models}

Our paper relates to a series of papers on conflict by Esteban and Ray, in short ER (e.g. Esteban and Ray (1994) or Esteban and Ray (forthcoming)). Their model generates conflict contributions in the fight for a public decision and provides a very general setting for the analysis of this conflict. A main difference between the two models is that group sizes are endogenous in our model. In addition, ER focus on situations in which conflict incentives are symmetric (with a few exceptions). We explicitly focus on asymmetric conflicts in which the distance felt by the ingroup towards the outgroup is independent from the distance felt in the other direction.

It is nonetheless interesting to compare our results regarding alienation with the conclusions reached in ER's classic conflict framework. Remember that in our model, alienation is chosen because there is a second order effect through shrinking group size and increased per capita effort that makes this strategy attractive. In our model alienation is only attractive if the group is sufficiently afraid of a trait change and therefore not too small. The conflict function that is used in the ER framework leads to a very similar effect without endogenizing group sizes. In particular, Esteban and Ray (forthcoming) show that the more active group reacts with more activism to an exogenously caused increase in the activism of the other group. In other words, individuals that benefit directly from activism would try to alienate the other group if their own group is more active already. Our results therefore seem to generalize at least partially.

A different model of conflict is provided by Glaeser (2005) who models the incentives of politicians to create messages of hatred against an outgroup. In his model, politicians send hate messages to gather support in a political contest. An important difference to our model is that Glaeser derives conditions under which the population does not check on the stories they are told by their politicians. If self-protection is relatively cheap compared to a verification of hate messages then politicians have a stronger incentive to send these messages. While our model is quite different, there is an interesting complementarity to the Glaeser (2005) framework. Corollary 2 identifies that leaders from both groups have an interest in alienating the other group. In the reading of Glaeser's (2005) framework we have therefore shown that leaders from both sides could actually have an incentive to cooperate in the creation of hatred. ${ }^{23}$

\footnotetext{
${ }^{23}$ The 1994 Rwanda Genocide is an important example how effective hate messages can
} 
A way to integrate the asymmetric information motivation of Glaeser's framework into our model would be to introduce restrictions on the lowering of $u_{i j}$ for the leader of group $i$. Alienation would then be captured by a decreasing cost for this claim of cultural superiority. Leaders on the two sides could then play in each others hands by supporting violence/terror and using the other group's violence to draw the picture of a barbaric culture on the other side of the clash. An example would be public displays of barbarism (September 11, Abu Graib, etc.) which create a real possibility for leaders in the other camp for spreading messages of hatred in their group. ${ }^{24}$

\section{Conclusion}

Our findings indicate that if the clash of cultures can be manipulated by leaders who gain rents from educational efforts then there is a danger of considerable radicalization. However, our model allows for a more in-depth analysis of the different characteristics of this radicalization. We identify mostly three channels through which the leader can increase the clash of cultures, namely

1. provision of beneficial cultural values that increase utility in-group;

2. claims of cultural superiority: the spread of negative attitudes towards other cultures that leads parents to be afraid of a trait change of their children;

3. cultural alienation: the spread of negative attitudes in other groups against the leader's own culture which leads to a shrinking in size of the leader's group but higher per capita effort.

By revealing these channels our paper uncovers a serious commitment problem between the population at large and its cultural leaders. On the one hand, the population can benefit massively from the provision of cultural

be. Yanagizawa (2009) estimates that $9 \%$ of the killings can be explained by the infamous hate radio station Radio RTLM which increased violence by 65 to $77 \%$ in villages with complete radio coverage.

${ }^{24}$ In our reading the real issue is not that stories of violence and cruelty are made up. What is fabricated by leaders is the link to the trait. Terrorists, for example, are seen as representing a group which suffers directly from their behavior. 
goods (art, moral guidance, rituals, entertainment); this channel is what makes the world go round. It cannot be stressed enough that the deeply rooted desire of humans to consume culture and to grow in that sense has carried wonderful blossoms throughout the years. On the other hand, the population is harmed by channels 2 and 3: cultural leaders have the incentive of spreading fear within the group and outside of the group to increase per capita expenditure. Precisely because we need to rely on cultural leaders for the provision of positive cultural goods (channel 1) it so hard to abolish those cultural leaders who abuse their position for rent seeking through channels 2 and 3 .

By claiming cultural superiority the second channel serves as a barrier towards adopting another culture. Our model shows that it is optimal for cultural leaders to maximize this barrier. This provides an explanation why cultural leaders put a lot of emphasis on their trait appearing to be very different and incompatible with other traits. There are some indicators that they can be successful. Many cultural/religious conflicts are characterized by rules of rejection or even harm of children who attempt to cross-breed with other cultures or religions. This goes as far as that parents prefer the death of their children to a change of trait.

While it is easy to understand that cultural leaders want barriers to avoid children of their flock changing trait, it is more surprising that they might benefit from the channel of cultural alienation. Cultural alienation acts as a barrier towards children of outsiders adopting the trait. The main reason why cultural leaders maintain this barrier towards their own trait is because they benefit indirectly through the general radicalization implied by alienation. In other words, our model shows that educational rents can lead to a bias towards small radicalized groups.

Pakistan is an example of this phenomenon. The massive influence of religious leaders in Pakistan is based on their command over rents and not votes. $^{25}$ In other words, religious leaders in Pakistan are powerful because Pakistani sects are (small) groups with fortified, closed ranks. Indeed, the per capital efforts are so high that sectarian divisions are militarized. In total, the resulting rents create a powerful force. The clergy backed Musharraf's coup and supported his policies towards India. They were, however, powerful enough to defy any attempt to reform madrasas system or eliminate Islamic

\footnotetext{
${ }^{25}$ Indeed, there is little control over votes: in the 1997 elections, the JUI of Fazlur Rahman was the only religious party to win seats in the 217-member National Assembly.
} 
militancy.

We see the Pakistani example as an exception only in degrees not in the mechanism. All around the world there are leaders who send messages that lock their own group in by alienating the outgroup. Our results indicate that the messages send by leaders should not be confused with the interest of the population. With all the talk of a "clash of civilizations" and the corresponding pictures on our TV screens Western products stay in high demand in the Middle East and are actually gathering market shares at breath-taking pace. ${ }^{26}$ If our model is applied to these countries, their general "modernization" is consistent with a shrinking, increasingly radicalized minority which follows religious leaders despite the considerable harm they inflict on them.

\section{References}

[1] Aigner, Dennis and Glen G. Cain (1977) "Statistical Theories of Discrimination in the Labor Markets" Industrial and Labor Relations Review 30(2): 175-87.

[2] Bar-Tal, Daniel and Daniela Labin (2001) "The effects of a major event on stereotyping: terrorist attacks in Israel and Israeli adolescents' perceptions of Palestinians, Jordans and Arabs", European Journal of Social Psychology 31, 265-280.

[3] Baker, William D. and John R. Oneal (2001) "Patriotism or Opinion Leadership?: The Nature and Origins of the "Rally 'Round the Flag" Effect", The Journal of Conflict Resolution 45(5) 661-687.

[4] Becker, G.S. (1971) The economics of discrimination University of Chicago Press, Chicago.

[5] Berrebi, Claude (2007) "Evidence About the Link Between Education, Poverty and Terrorism Among Palestinians" Peace Science and Public Policy 13(1).

\footnotetext{
${ }^{26}$ Cocal Cola per capita product consumption (just as an example) was growing by 63 percent in Egypt, 22 percent in Morocco and 275 percent in Pakistan between 1999 and 2009. Source: Coca Cola Company, EURASIA \& AFRICA Operating Group 2010, author's calculation.
} 
[6] Berrebi, Claude and Esteban Klor (2008) "Are Voters Sensitive to Terrorism? Direct Evidence from the Israeli Electorate" American Political Science Review 102(3): 279-301.

[7] Bisin, Alberto and Thierry Verdier (2001) "The economics of cultural transmission and the dynamics of preferences" Journal of Economic Theory 97: 298-319.

[8] Bisin, Alberto, Giorgio Topa and Thierry Verdier (2008) "Cultural Transmission, Socialization and the Population Dynamics of Multiple State Traits Distributions" International Journal of Economic Theory 5: 139-154.

[9] Black, Dan A. (1995) "Discrimination in an Equilibrium Search Model", Journal of Labor Economics 13(2): 309-33

[10] Bueno de Mesquita, Ethan (2005) "The Quality of Terror", American Journal of Political Science 49(3): 515-530

[11] Canetti-Nisim, Daphna, Eran Halperin, Keren Sharvit and Stevan E. Hobfoll (2009) "A New Stress-Based Model of Political Extremism. Personal Exposure to Terrorism, Psychological Distress, and Exclusionist Political Attitudes", Journal of Conflict Resolution 53(3): 363-389.

[12] Cohen, F., S. Solomon, M. Maxfield, T. Pyszczynski and J. Greenberg (2004) "Fatal Attraction: The Effects of Mortality Salience on Evaluations of Charismatic, Task-Oriented, and Relationship-Oriented Leaders", Psychological Science 15(12): 846 - 851.

[13] Colaresi, Michael (2004) "When Doves Cry: International Rivalry, Unreciprocated Cooperation, and Leadership Turnover", American Journal of Political Science 48(3): 555-570.

[14] Cornell, Bradford and Ivo Welch (1996) "Culture, Information and Screening Discrimination" Journal of Political Economy 104(3): 54271 .

[15] Dávila, Alberto and Marie T. Mora (2005) "Changes in the earnings of Arab men in the US between 2000 and 2002" Journal of Population Economics 18: 587-601. 
[16] Das, E. , B.J. Bushman, M.D.Bezemer, P. Kerhof and I.E.Vermeulen (2009) "How terrorism news reports increase prejudice against outgroups: A Terror management account", Journal of Experimental Psychology 45: 453-459.

[17] Esteban, Joan and Debraj Ray (forthcoming) "A Model of Ethnic Conflict" The Journal of the European Economic Association

[18] Esteban, Joan and Debraj Ray (1994) "On the Measurement of Polarization" Econometrica 62(4): 819-851.

[19] Freyd, Jennifer J. (2002) "In the Wake of Terrorist Attack, Hatred May Mask Fear" Analyses of Social Issues and Public Policy 2(1): 5-8.

[20] Glaeser, Edward L. (2005) "The Political Economy of Hatred", The Quarterly Journal of Economics 120(1): 45-86

[21] Greenberg, J. Pyszczynsji, T. and S. Solomon (1986) "The causes and consequences of a need for self-esteem: A terror management theory" in R.F.Baumeister (ed) Public Self and Private Self (pp. 189-212). NewYork, Springer Verlag.

[22] Hauk, Esther and Maria Saez-Marti (2002) "On the cultural transmission of corruption", Journal of Economic Theory 107: 311-335.

[23] Hitlan, Robert T. and Kimberly Carrillo and Michael A. Zárate and Shelley N. Aikman (2007) "Attitudes Toward Immigrant Groups and the September 11 Terrorist Attacks" Peace and Conflict: Journal of Peace Psychology 13(2): 135-152.

[24] Huntington, Samuel P. (1993) "The Clash of Civilizations?", Foreign Affairs.

[25] Huntington, Samuel P. (1996) The Clash of Civilizations and the Remaking of World Order.

[26] Kam, Cindy D. and Donald R. Kinder (2007) "Terror and Ethnocentrism: Foundations of American Support for the War on Terrorism" The Journal of Politics 69(2): 320-338. 
[27] Kaushal, Neeraj, Robert Kaestner and Cordelia Reimers (2007) "Labor Market Effects of Septmebr 11th on Arab and Muslim Residents in the United States", J Human Resources XLII(2): 275-308.

[28] Krueger, Alan B. and Jitka Maleckova (2002) "Education, Poverty and Terrorism: Is There a Causal Connection?" Journal of Economic Perspectives 17(4): 119-44.

[29] Lai, Brian and Dan Reiter (2005) "Rally 'Round the Union Jack? Public Opinion and the Use of Force in the United Kingdom, 1948-2001", International Studies Quarterly 49, 255-272.

[30] Landau, M.J., S. Solomon, J. Greenberg, F. Cohen, T. Pyszczynski, J. Arndt, C. Miller, D. Ogilvie and A. Cook (2004) "Deliver us from Evil: The Effects of Mortality Salience and Reminders of 9/11 on Support for President George W. Bush " Personality and Social Psychology Bulletin 30(9): 1136-1150.

[31] McCauley, C. (2007) "Psychological Issues in Understanding Terrorism and the Response to Terrorism" chapter 2 of Psychology of Terrorism, edited by B. Bongar, L. Brown, L. Beutler, J. Brecehnridge and P. Zimbardo, Oxford University Press.

[32] Montgomery, James, D. (2008) "Intergenerational Cultural Transmission as an Evolutionary Game", mimeo, Department of Sociology, University of Wisconsin-Madison.

[33] Morgan, John and Felix Vardy (2009) "Diversity in the Workplace", American Economic Review 99(1): 472-485.

[34] Oswald, Debra L. (2005) "Understanding Anti-Arab Reactions Post9/11: The Role of Threats, Social Categories and Personal Ideologies" Journal of Applied Social Psychology 35(9): 1775-1799.

[35] Phelps, Edmund S. (1972) "The Statistical Theory of Racism and Sexism." American Economic Review 62(4): 659-61.

[36] Rabby, Faisal (2007) "The Post-9/11 Labor Markets for "Muslims" in the West - Evidence from the USA and the UK" Working Paper Department of Economics, Rutgers University. 
[37] Rosen, Asa (1997) "An Equilibrium Search-Matching Model of Discrimination" European Economic Review 41(8): 1589-1613.

[38] Sasaki, Masaru (1999) "An Equilibrium Search Model with Coworker Discrimination" Journal of Labor Economics 17(2): 377-407.

[39] Sen, Amartrya (2006) Identity and Violence: The Illusion of Destiny, W.W.Norton \& Comany, Inc. New York.

[40] Sheridan, Lorraine P (2006) "Islamophobia Pre- and Post-September 11th, 2001 " Journal of Interpersonal Violence 21 (3): 317-336.

[41] Solonon, S. Greenberg, J. and T Pyszczynski (1991) "A terror management theory of social behavior: the psychological functions of self-esteem and cultural worldviews" in M.Zanna (ed.) Advances in Experimental Social Psychology 24, 93-159. Orlando, FL. Academic Press

[42] Yanagizawa, David (2009) "Propaganda and Conflict: Theory and Evidence From the Rwandan Genocide", mimeo, Stockholm School of Economics

\section{A Proof of Proposition 1}

Given our underlying model we use (8) and (10) to derive that $\frac{\partial \Delta_{2}}{\partial f_{2}}=1$ and $\frac{\partial q^{*}}{\partial f_{2}}=-\frac{f_{1}+\left(w_{1}-w_{2}\right)}{\left(f_{1}+f_{2}\right)^{2}}$. Therefore, the derivative of (11) with respect to $f_{2}$ is given by

$$
\frac{\partial U_{2 l e a d e r}}{\partial f_{2}}=\Delta_{2} q^{* 2}\left(1-q^{*}\right)-\frac{1}{2} \Delta_{2}^{2} q^{*}\left(2-3 q^{*}\right) \frac{f_{1}+\left(w_{1}-w_{2}\right)}{\left(f_{1}+f_{2}\right)^{2}}
$$

We can evaluate the sign by looking at the sign of

$$
q^{*}\left(1-q^{*}\right)-\frac{1}{2} \Delta_{2}\left(2-3 q^{*}\right) \frac{f_{1}+\left(w_{1}-w_{2}\right)}{\left(f_{1}+f_{2}\right)^{2}}
$$

After plugging in $\Delta_{2}$ and the equilibrium $q^{*}(8)$ and (10) we get

$$
\frac{3}{2} \frac{\left(f_{2}-\left(w_{1}-w_{2}\right)\right)\left(f_{1}+\left(w_{1}-w_{2}\right)\right)^{2}}{\left(f_{1}+f_{2}\right)^{3}}>0
$$


Hence, religious leaders would always like to set the maximal $f_{2}$ possible. We now turn to the question how an increase in $f_{2}$ affects the utility of the minority. This depends whether the increase in $f_{2}$ is due to an increase in $u_{22}$ or a decrease in $u_{21}$. The utility of the minority is given by

$$
\begin{aligned}
U_{2} & =V^{22}-\left(1-\Delta_{2} q^{*}\right) \Delta_{2} q^{*}-\frac{1}{2}\left(\Delta_{2} q^{*}\right)^{2} \\
& =V^{22}-\Delta_{2} q^{*}+\frac{1}{2}\left(\Delta_{2} q^{*}\right)^{2}
\end{aligned}
$$

so that

$$
\frac{\partial U_{2}}{\partial u_{21}}=-\frac{\partial \Delta_{2} q^{*}}{\partial u_{21}}\left(1-\Delta_{2} q^{*}\right) .
$$

In words, an increase in cultural superiority (decreasing $u_{21}$ ) harms utility if it leads to an increase in equilibrium educational effort. This is the case if

$$
\frac{\partial \Delta_{2} q^{*}}{\partial u_{21}}<0
$$

or

$$
-\frac{\Delta_{1}}{\Delta_{1}+\Delta_{2}}+\frac{\Delta_{1} \Delta_{2}}{\left(\Delta_{1}+\Delta_{2}\right)^{2}}<0
$$

which is always the case.

For a change in $u_{22}$ the calculation is

$$
\frac{\partial U_{2}}{\partial u_{22}}=1-\frac{\partial \Delta_{2} q^{*}}{\partial u_{22}}\left(1-\Delta_{2} q^{*}\right)>0 .
$$

The minority always benefits from an increase in $u_{22}$ and suffers from a decrease in $u_{21}$.

\section{B Proof of Proposition 2}

Note that $\frac{\partial \Delta_{2}}{\partial f_{1}}=0$ so that the change in indirect utility of the cultural leader is given by

$$
\frac{\partial U_{2 l e a d e r}}{\partial f_{1}}=\frac{1}{2} \Delta_{2}^{2} q^{*}\left(2-3 q^{*}\right) \frac{\partial q^{*}}{\partial f_{1}}
$$

which is positive for all $q^{*}<\frac{2}{3}$ as $\frac{\partial q^{*}}{\partial f_{1}}>0$.

The utility of the minority is given by 


$$
U_{2}=P^{22} V^{22}+P^{21} V^{21}-\frac{1}{2} d_{2}^{2}
$$

which can be written as

$$
U_{2}=V^{22}-q\left(1-d_{2}\right) \Delta_{2}-\frac{1}{2} d_{2}^{2}
$$

in equilibrium $d_{2}=\Delta_{2} q^{*}$

$$
U_{2}=V^{22}-\left(1-\Delta_{2} q^{*}\right) \Delta_{2} q^{*}-\frac{1}{2}\left(\Delta_{2} q^{*}\right)^{2} .
$$

Note that the change of utility with $\Delta_{2} q^{*}$ is

$$
\frac{\partial U_{2}}{\partial \Delta_{2} q^{*}}=-1+\Delta_{2} q^{*}<0
$$

as $\Delta_{2} q^{*}<1$.

Now we are ready to show that cultural alienation is not in the minority's interest. Cultural dislike towards the minority, $f_{1}$, does not affect $V^{22}$ but affects the minority's utility through $\Delta_{2} q^{*}=\frac{\Delta_{1} \Delta_{2}}{\Delta_{1}+\Delta_{2}}$ as follows

$$
\begin{aligned}
\frac{\partial \Delta_{2} q^{*}}{\partial f_{1}} & =\frac{\Delta_{2}\left(\Delta_{1}+\Delta_{2}\right)-\Delta_{1} \Delta_{2}}{\left(\Delta_{1}+\Delta_{2}\right)^{2}} \frac{\partial \Delta_{1}}{\partial f_{1}} \\
& =\frac{\Delta_{2}^{2}}{\left(\Delta_{1}+\Delta_{2}\right)^{2}}>0
\end{aligned}
$$

which means that

$$
\frac{\partial U_{2}}{\partial f_{1}}<0
$$

\section{Proof of Proposition 3}

We know that

$$
\begin{aligned}
\frac{\partial U_{2 l e a d e r}}{\partial f_{2}}= & \Delta_{2} q^{* 2}\left(1-q^{*}\right)-\frac{1}{2} \Delta_{2}^{2} q^{*}\left(2-3 q^{*}\right) \frac{f_{1}+\left(w_{1}-w_{2}\right)}{\left(f_{1}+f_{2}\right)^{2}} \\
= & \Delta_{2}\left(\frac{\Delta_{1}}{\Delta_{1}+\Delta_{2}}\right)^{2}\left(1-\frac{\Delta_{1}}{\Delta_{1}+\Delta_{2}}\right) \\
& -\frac{1}{2} \Delta_{2}^{2} \frac{\Delta_{1}}{\Delta_{1}+\Delta_{2}}\left(2-3 \frac{\Delta_{1}}{\Delta_{1}+\Delta_{2}}\right) \frac{\Delta_{1}}{\left(\Delta_{1}+\Delta_{2}\right)^{2}} \\
= & \frac{3}{2}\left(\Delta_{1}+\Delta_{2}\right)^{-4} \Delta_{2}^{2} \Delta_{1}^{3}
\end{aligned}
$$


and

$$
\begin{aligned}
\frac{\partial U_{\text {leader }}}{\partial f_{1}} & =\frac{1}{2} \Delta_{2}^{2} \frac{\Delta_{1}}{\Delta_{1}+\Delta_{2}}\left(2-3 \frac{\Delta_{1}}{\Delta_{1}+\Delta_{2}}\right) \frac{\partial q^{*}}{\partial f_{1}} \\
& =\frac{1}{2} \Delta_{2}^{2} \frac{\Delta_{1}}{\Delta_{1}+\Delta_{2}}\left(2-3 \frac{\Delta_{1}}{\Delta_{1}+\Delta_{2}}\right)\left(\frac{1}{\Delta_{1}+\Delta_{2}}-\frac{\Delta_{1}}{\left(\Delta_{1}+\Delta_{2}\right)^{2}}\right) \\
& =\frac{1}{2}\left(\Delta_{1}+\Delta_{2}\right)^{-4}\left(2 \Delta_{2}-\Delta_{1}\right) \Delta_{2}^{3} \Delta_{1}
\end{aligned}
$$

If raising $f_{1}$ and $f_{2}$ cost the same the leader prefers raising $f_{2}$ if

$$
\frac{\partial U_{2 l e a d e r}}{\partial f_{2}}>\frac{\partial U_{2 l e a d e r}}{\partial f_{1}}
$$

or

$$
3 \Delta_{1}^{2}>\left(2 \Delta_{2}-\Delta_{1}\right) \Delta_{2}
$$

so that the leader is indifferent between the two at

$$
3 \Delta_{1}^{2}+\Delta_{1} \Delta_{2}-2 \Delta_{2}^{2}=0
$$

or

$$
\Delta_{1}=\frac{-\Delta_{2} \pm \sqrt{\Delta_{2}^{2}+24 \Delta_{2}^{2}}}{6}
$$

as only positive numbers make sense we therefore have

$$
\Delta_{1}=\frac{2}{3} \Delta_{2}
$$

which implies that the leader prefers raising $f_{2}$ for all

$$
\begin{aligned}
\Delta_{1} & >\frac{2}{3} \Delta_{2} \\
& \Longleftrightarrow q^{*}>\frac{2}{5} .
\end{aligned}
$$

\section{Proof of Proposition 4}

Note first that

$$
\begin{aligned}
& \frac{\partial \Delta_{2} q^{*}}{\partial\left(w_{1}-w_{2}\right)}=1-2 q^{*} \\
& \frac{\partial q^{*}}{\partial\left(w_{1}-w_{2}\right)}=\frac{1}{f_{1}+f_{2}}
\end{aligned}
$$


with $U_{2 l e a d e r}=\frac{1}{2}\left(\Delta_{2} q^{*}\right)^{2}\left(1-q^{*}\right)$ the long term utility change with wage discrimination is then

$$
\begin{aligned}
\frac{\partial U_{\text {2leader }}}{\partial\left(w_{1}-w_{2}\right)} & =\frac{1}{2} 2\left(\Delta_{2} q^{*}\right)\left(1-q^{*}\right)\left(1-2 q^{*}\right)-\frac{1}{f_{1}+f_{2}} \frac{1}{2}\left(\Delta_{2} q^{*}\right)^{2} \\
& =\left[2\left(1-2 q^{*}\right)-q^{*}\right] \frac{1}{2}\left(\Delta_{2} q^{*}\right)\left(1-q^{*}\right)
\end{aligned}
$$

The maximum is therefore at $q^{*}=\frac{2}{5}$.

\section{E Proof of Proposition 5}

The leader would like to increase alienation as long as this increases his utility, namely

$$
\frac{\partial U_{2 l e a d e r}}{\partial f_{1}}=\Delta_{2} q^{2}(1-q) \frac{\partial \Delta_{2}}{\partial f_{1}}+\frac{1}{2} \Delta_{2}^{2} q(2-3 q) \frac{\partial q}{\partial f_{1}}>0
$$

Using the equilibrium $q$ defined by (12) and $\Delta_{2}=f_{2}-\alpha f_{1}$ in the first order condition for the religious leader (22) we get after some algebra

$$
\frac{\partial U_{2 l e a d e r}^{S}}{\partial f_{1}}=\frac{1}{2} \Delta_{2}^{2} q \frac{(1+\alpha)}{\left(f_{1}+f_{2}\right)^{3}}\left[\left(-2 \alpha f_{1}^{2}-f_{1} f_{2}(1+5 \alpha)+2 f_{2}^{2}\right]\right.
$$

We have to look at the sign of the square bracket only which is positive for

$$
f_{1}<f_{1}^{\alpha}=\frac{f_{2}}{4 \alpha}\left(\sqrt{(1+5 \alpha)^{2}+16 \alpha}-(1+5 \alpha)\right)
$$

Hence the optimal level of alienation is given by $f_{1}^{\alpha}$ and we can show that

$$
\frac{\partial f_{1}^{\alpha}}{\partial \alpha}=\frac{f_{2}}{4 \alpha^{2}}\left[1-\frac{1+13 \alpha}{\sqrt{(1+5 \alpha)^{2}+16 \alpha}}\right]<0
$$




\section{F $\quad$ Proof of Proposition 6}

We first prove the different equilibria outcomes.

1. Let condition (17) hold and suppose for contradiction that separation is an equilibrium outcome. Then the optimal fear level $f_{1}^{S}$ is given by (14). The minority will indeed choose not to integrate if $\alpha f_{1}^{S}>$ $w_{1}-w_{2}$. Replacing $f_{1}^{S}$ by its value this condition can be rewritten as $f_{2}>\frac{1+3 \alpha}{2 \alpha}\left(w_{1}-w_{2}\right)$ which contradicts condition (17).

2. Condition (18) is equivalent to $\alpha f_{1}^{I}>\left(w_{1}-w_{2}\right)$ hence the minority will be better off in the minority sector.

3. When both equilibria are feasible it is easy to see that $q^{I}<q^{S}$ since $q^{I}>q^{S}$ would require $\alpha f_{1}^{I}>w_{1}-w_{2}$ which would induce the minority to switch to the minority sector and make the integration equilibrium disappear. To see which equilibrium is chosen by the leader we have to compare the leader's utilities in the different equilibria, namely

$$
U_{2 l e a d e r}^{S}=\frac{1}{2}\left(f_{2}-\left(w_{1}-w_{2}\right)\right)^{2}\left(q^{S}\right)^{2}\left(1-q^{S}\right)
$$

with

$$
U_{2 l e a d e r}^{I}=\frac{1}{2}\left(f_{2}-\alpha f_{1}^{I}\right)^{2}\left(q^{I}\right)^{2}\left(1-q^{I}\right)
$$

Using the equilibrium values for $q^{I}$ and $q^{S}$ we get

$$
\begin{aligned}
& U_{2 l e a d e r}^{S}=\frac{1}{2}\left(f_{2}-\left(w_{1}-w_{2}\right)\right)^{2} \frac{4}{27} \\
U_{2 \text { leader }}^{I}= & \frac{1}{2}\left(f_{2}-\alpha f_{1}^{I}\right)^{2}\left(\frac{(1+\alpha) f_{1}^{I}}{f_{1}^{I}+f_{2}}\right)^{2}\left(\frac{f_{2}-\alpha f_{1}^{I}}{f_{1}^{I}+f_{2}}\right) \\
= & \frac{1}{2}\left(\frac{f_{2}-\alpha f_{1}^{I}}{f_{1}^{I}+f_{2}}\right)^{3}\left((1+\alpha) f_{1}^{I}\right)^{2}
\end{aligned}
$$

where $f_{1}^{I}$ is given by (16)). If both equilibria exist the leader is better off in the separation equilibrium if $U_{2 l e a d e r}^{S}>U_{2 l e a d e r}^{I}$ or equivalently if

$$
4\left(f_{2}-\left(w_{1}-w_{2}\right)\right)^{2}\left(f_{1}^{I}+f_{2}\right)^{3}-27\left(f_{2}-\alpha f_{1}^{I}\right)^{3}\left((1+\alpha) f_{1}^{I}\right)^{2}>0
$$


Replacing $f_{1}^{I}$ by its value in (24) and rearranging we obtain condition (19), namely

$$
(1-\sqrt{B}) f_{2}>\left(w_{1}-w_{2}\right)
$$

where $B$ is defined by

$$
B=\frac{27}{64} \alpha(\alpha+1)^{2}\left(5 \alpha+1-\sqrt{25 \alpha^{2}+26 \alpha+1}\right)^{2} \frac{\left(5 \alpha+5-\sqrt{25 \alpha^{2}+26 \alpha+1}\right)^{3}}{\left(\sqrt{25 \alpha^{2}+26 \alpha+1}-(\alpha+1)\right)^{3}}
$$

Straightforward but tedious calculations show that $B<1$.

\section{G $\quad$ Proof of Proposition 7}

We first look at condition (18) and rewrite it as

$$
\frac{f_{2}}{4}\left(\sqrt{(1+5 \alpha)^{2}+16 \alpha}-(1+5 \alpha)\right)>\left(w_{1}-w_{2}\right)
$$

It is immediate that a lower $\left(w_{1}-w_{2}\right)$ makes the condition more easily satisfied. It is also easy to see that the left hand side increases in $f_{2}$ and increases in $\alpha$.

Next we look at condition (19). Since $B<1$, condition (19) is more likely to bind with higher $f_{2}$.

To know how the condition changes with $\alpha$ we need to look at the sign of the derivative of $B$ with respect to these parameters. We rewrite $B$ as

$B=-\frac{27}{64} \alpha(\alpha+1)^{2}\left(5 \alpha+1-\sqrt{25 \alpha^{2}+26 \alpha+1}\right)^{2} \frac{\left(5 \alpha+5-\sqrt{25 \alpha^{2}+26 \alpha+1}\right)^{3}}{\left(\alpha+1-\sqrt{25 \alpha^{2}+26 \alpha+1}\right)^{3}}$

First observe that the derivative of $\left(5 \alpha+5-\sqrt{25 \alpha^{2}+26 \alpha+1}\right)^{3}>0$ with respect to $\alpha$ is negative, because $\left(5-\frac{25 \alpha+13}{\sqrt{25 \alpha^{2}+26 \alpha+1}}\right)<0$.

Now let's look at the derivative of the remaining terms depending on $\alpha$, namely of

$$
\frac{\alpha(\alpha+1)^{2}\left(5 \alpha+1-\sqrt{25 \alpha^{2}+26 \alpha+1}\right)^{2}}{\left(\alpha+1-\sqrt{25 \alpha^{2}+26 \alpha+1}\right)^{3}}<0
$$


with respect to $\alpha$. Observe that $\alpha(\alpha+1)^{2}=\alpha^{3}+2 \alpha^{2}+\alpha$. Hence the sign of the derivative is equal to the sign of

$$
\begin{aligned}
& \left(\alpha+1-\sqrt{25 \alpha^{2}+26 \alpha+1}\right)\left(3 \alpha^{2}+4 \alpha+1\right)\left(5 \alpha+1-\sqrt{25 \alpha^{2}+26 \alpha+1}\right)^{2} \\
& +\left(\alpha+1-\sqrt{25 \alpha^{2}+26 \alpha+1}\right)\left(5 \alpha+1-\sqrt{25 \alpha^{2}+26 \alpha+1}\right) \\
& \times\left(5-\frac{50 \alpha+26}{2 \sqrt{25 \alpha^{2}+26 \alpha+1}}\right) \\
& -3 \alpha(\alpha+1)^{2}\left(5 \alpha+1-\sqrt{25 \alpha^{2}+26 \alpha+1}\right)^{2}\left(1-\frac{50 \alpha+26}{2 \sqrt{25 \alpha^{2}+26 \alpha+1}}\right) \\
& =\frac{\alpha+1}{\sqrt{25 \alpha^{2}+26 \alpha+1}} \\
& \times\left(\begin{array}{c}
\sqrt{25 \alpha^{2}+26 \alpha+1}\left((1+3 \alpha)\left(25 \alpha^{2}+26 \alpha+1\right)+175 \alpha^{3}+1+49 \alpha+191 \alpha^{2}\right) \\
-\left(1250 \alpha^{4}+2+972 \alpha^{2}+104 \alpha+2120 \alpha^{3}\right)
\end{array}\right)
\end{aligned}
$$

Looking at the bracket we need to compare

$$
\sqrt{25 \alpha^{2}+26 \alpha+1}\left((1+3 \alpha)\left(25 \alpha^{2}+26 \alpha+1\right)+175 \alpha^{3}+1+49 \alpha+191 \alpha^{2}\right)
$$

with

$$
1250 \alpha^{4}+2+972 \alpha^{2}+104 \alpha+2120 \alpha^{3} .
$$

Taking squares and looking at the difference we get

$$
256 \alpha^{2}\left(375 \alpha^{4}+776 \alpha^{3}+526 \alpha^{2}+128 \alpha+3\right)>0
$$

So the entire sign of the derivative is positive. Hence we have a sign change in the derivative for both expressions and therefore we get that increasing $\alpha$ leads to a lower $B$, so the condition becomes less binding.

Finally we look at condition (17). It is easy to see that its right hand side, namely $\frac{1+3 \alpha}{2 \alpha}\left(w_{1}-w_{2}\right)$, increases in $\left(w_{1}-w_{2}\right)$ and decreases in $\alpha$. Hence the condition is more easily violated when the opposite happens. 